\title{
06 CAN BLOOD ALCOHOL CONCENTRATION OF ROAD TRAFFIC INJURY PATIENTS DECREASE AFTER INFORMATION EDUCATION COMIMUNICATION CAMPAIGN IN VIETNAM
}

doi:10.1136/injuryprev-2012-040590r.6

TNL Tran, TL Nguyen, MA Luong, TOT Khieu. Health Environment Management Agency, Ministry of Health

Background Road traffic injury (RTI) is the leading cause of death and disability in the world. Drink-driving is one of risk factor of fatal injury related traffic road in the world and in Viet Nam.

Objectives and Methods Determine blood alcohol concentration (BAC) of RTIs patients in 2 phases in 5 hospitals. Phase 1 (5 months) with 1453 patients, phase 2 (6 months) with 2640 patients was conducted pre and post-intervention of IEC campaign on drinking-driving. RTIs patient was taken blood for BAC testing. Results RTIs patients in phase 2 with high BAC in tendency decrease, $\mathrm{BAC}<50 \mathrm{mg} / \mathrm{dl}$ in phase 1 with rate of $16.5 \%$ to $33.8 \%$ in phase 2 , and $B A C \geq 50 \mathrm{mg} / \mathrm{dl}$ in phase 1 of $83.5 \%$ to $66.2 \%$ in phase 2. Rate of motorbike drivers with $\mathrm{BAC} \geq 50 \mathrm{mg} / \mathrm{dl}$ pre-intervention lower $7.2 \%$ than post-intervention. Rate of motorbike drivers with $\mathrm{BAC} \geq 50 \mathrm{mg} / \mathrm{dl}$ had RTIs from 16:30-19:30 lower 9.1\% than preintervention. Rate of 20-29 of age drink-driving exceeded the limit of legal and with $\mathrm{BAC} \geq 50 \mathrm{mg} / \mathrm{dl}$ had RTIs from 19:30 were not decreased.

Significance It is vital to continue strengthening interventions; developing regulations of using and selling alcohol, focusing on age of 20-29; monitoring and checking random alcohol on the highways, from 19:00; conducting researches on RTIs and drinking for recommendations. 